\title{
High-intensity exercise is associated with a better nutritional status in anorexia nervosa
}

\author{
Melissa Rizk ${ }^{1}$ | Laurence Kern ${ }^{2}$ | Christophe Lalanne ${ }^{3}$ | Mouna Hanachi ${ }^{4}$ | \\ Jean-Claude Melchior ${ }^{4,5}$ | Claude Pichard ${ }^{6}$ | Lama Mattar ${ }^{7}$ | EVHAN Group ${ }^{*}$ | \\ Sylvie Berthoz ${ }^{8 \dagger} \mid$ Nathalie Godart ${ }^{1,9,10 \dagger}$
}

${ }^{1}$ CESP, INSERM, University of ParisDescartes, Paris, France

${ }^{2}$ Laboratory EA 2931, CERSM, UFRSTAPS, Nanterre, France

${ }^{3}$ University Paris Diderot, Paris, France

${ }^{4}$ Nutrition-TCA Unit, Hospital Poincaré, APHP, Garches, France

${ }^{5}$ University of Versailles Saint-

Quentin-en-Yvelines, France

${ }^{6}$ Clinical Nutrition, University Hospital of Geneva, Geneva, Switzerland

${ }^{7}$ Natural Sciences department, nutrition program, Lebanese American University, Beirut, Lebanon

${ }^{8}$ CESP, INSERM, University of Paris-Sud, UVSQ, Université Paris-Saclay, Villejuif,

France

${ }^{9}$ Psychiatry Unit, Institut Mutualiste

Montsouris, Paris, France

${ }^{10}$ Adolescent and young adult mental health Unit, Fondation Santé des étudiants de France, Paris, France

\section{Correspondence}

Rizk Melissa, PhD, CESP, INSERM, University of Paris-Descartes, USPC, 42 Boulevard Jourdan, Paris 75014, France. Email: melissarizk@hotmail.com

Funding information

French Ministry of Health, Grant/Award

Number: AOM11197

\begin{abstract}
Objective: Our aim is to investigate the links between duration and intensity of exercise and the nutritional status in terms of body composition in acute anorexia nervosa (AN) patients.

Method: One hundred ninety-one hospitalized women suffering from AN were included. Exercise duration and intensity were assessed using a semistructured questionnaire. Body composition was measured using bioelectrical impedance. Linear multiple regression analyses were carried out using body mass index, fat-free mass index, and fat mass index as dependent variables and including systematically exercise duration, exercise intensity, and other confounding variables described in the literature that were significantly associated with each dependent variable in univariate analysis.
\end{abstract}

Results: A lower BMI was linked to lower exercise intensity, AN restrictive type, and presence of amenorrhea. A lower FFMI was linked to lower exercise intensity, older age, AN restrictive type, and premenarchal AN. Duration of exercise was not linked to the nutritional status.

Conclusions: Exercising at higher intensity in AN is associated with a better nutritional status, thus, a better resistance to starvation. The impact of therapeutic physical activity sessions, adapted in terms of exercise intensity and patient's clinical status, should be evaluated during nutrition rehabilitation.

\section{KEYWORDS}

Anorexia nervosa, Exercise, Nutritional status, Body composition, Body Mass Index

\section{1 | INTRODUCTION}

Anorexia nervosa (AN) is a life-threatening eating disorder with several somatic and psychiatric comorbidities

"Membership of "EVHAN group" is provided in the Acknowledgments. †Sylvie Berthoz and Nathalie Godart have contributed equally to this work.
(Roux, Chapelon, \& Godart, 2013; Woodside \& Staab, 2006). These complications are essentially due to the extent of weight loss, malnutrition, and the duration of the disorder (Miller et al., 2005). AN has a severe impact on nutritional status, which is reflected by a marked decrease in body mass index (BMI) and changes in body fat, impacting long-term outcome (Probst, Goris, 
Vandereycken, \& Van Coppenolle, 1996). The lower the BMI at admission to AN inpatient unit, the worst the prognosis is (Hebebrand et al., 1997; Huas et al., 2011).

Excessive physical exercise is a main symptom of AN and a common restrictive behavior used by patients to lose weight (American Psychiatric Association, 2013). It also interferes with nutrition rehabilitation and increases the risk of short-term somatic complications such as fractures and bruises (Rizk, Kern, Godart, \& Melchior, 2014). It is associated with poor clinical and therapeutic outcomes (El Ghoch et al., 2013; Ng, Ng, \& Wong, 2013; Solenberger, 2001). There is no international consensus on a clear and valid definition of excessive exercise in AN. However, the notions of exercise and physical activity are distinct. In fact, exercise is a subgroup of physical activity: It is structured, planned, voluntary, repetitive, and not always pleasant (WHO, 2010). Physical activity includes any bodily movement produced by skeletal muscles that results in energy expenditure (Caspersen, Powell, \& Christenson, 1985). Historically in the literature, exercise in AN has mainly been considered as a problematic activity that should be limited or even completely banned, especially during the acute phase of the disorder (Rizk, 2015). However, recent literature is showing that exercise could be a component in the treatment of several mental disorders (Zschucke, Gaudlitz, \& Strohle, 2013) including eating disorders (Hausenblas, Cook, \& Chittester, 2008; Vancampfort et al., 2014) and AN in particular (Ng et al., 2013; Zunker, Mitchell, \& Wonderlich, 2011). Nevertheless, data concerning the link between exercise (when not defined as an excessive physical activity) and nutritional status in AN are scarce and contradictory. Physical exercise has been associated with either lower (Hechler et al., 2008) or higher (Casper, Schoeller, Kushner, Hnilicka, \& Gold, 1991) BMI in AN.

The most described animal model combining food restriction and elevated physical activity is the "activitybased anorexia" model (ABA model; Adan et al., 2011). This model shows that rodents who have free access to a running wheel will develop hyperactivity in response to a limited food supply (1-2 hr of food access per day). However, recent findings in this animal model suggest elements in favor of a protective effect of exercise in case of food restriction (Achamrah et al., 2016). Mequinion et al. (Méquinion et al., 2015) evaluated the impact of voluntary physical activity on two groups of mice that were both food restricted. The first group had access to a running wheel whereas the second group did not. Short-term results showed that the first group of mice adapted quicker to food restriction and despite reaching a critical point of body weight earlier, they also stabilized their weight faster compared with the second group. Longterm results showed that the first group had a better use of ingested glucose and less-fat oxidation. They finally hypothesized that physical activity could have positive effects on the global adaptation to the severe condition of food restriction found in patients with AN (Méquinion et al., 2015).

In addition, it seems that adapted exercise programs are associated with improved functional capacities in patients with AN: A high-intensity resistance training program (tailored to the recommendations for adolescents with AN) improved muscular strength in the whole body and the ability of patients to perform daily tasks (Fernandez-del-Valle et al., 2014).

The purpose of this study is to investigate the links between physical exercise, in terms of duration and intensity and nutritional status in terms of BMI, fat-free mass index (FFMI), and fat mass index (FMI) in hospitalized patients with AN. To our knowledge, no research to date has investigated this question.

\section{2 | MATERIALS AND METHODS}

\section{1 | Ethical statement}

This study was part of a larger multicentered study named EVHAN (Evaluation of Hospitalization for AN, Eudract number: 2007-A01110-53, registered in Clinical trials). The study protocol was approved by the Ile-de-France III Ethics Committee and the CNIL (Commission nationale de l'informatique et des libertés). Written informed consent was obtained from each patient before inclusion and from the parents of those who were under 18 years old.

\section{2 | Participants}

Prior to inclusion in the study, all participants were hospitalized in an inpatient care unit for life-threatening physical and/or mental states (including a body mass index (BMI) below 14 and/or rapid weight loss and/or compromised vital functions, severe depression, highsuicide risk, chronic undernutrition with low weight, and/or failure of outpatient care). Inclusion criteria of EVHAN were patients aged 8-65 years old referred for an acute AN episode to one of the 11 French specialized inpatient treatment facilities participating in the EVHAN study. Individuals were excluded if they (a) refused to participate in the research; (b) had insufficient knowledge of the French language; (c) were suffering, in addition to their eating disorder, from potentially confounding somatic pathologies (diabetes, Crohn's disease, or metabolic disorders); (d) had already been included in the protocol during a previous hospitalization. 
Two-hundred and thirty-three patients were included in the EVHAN study between April 2009 and July 2012. Current AN diagnosis was based on the DSM-IV-TR criteria and assessed using the CIDI 3.0 (WHO, 1997) with the following BMI criteria: BMI < 10th percentile up to 17 years of age and BMI $<17.5$ for 17 years of age and above. Purging symptoms were evaluated using the Eating Disorder Examination Questionnaire (Cooper, Cooper, \& Fairburn, 1989). At inclusion, (a) seven patients did not meet DSM-IV-TR Criterion A. However, two of them had shifted from a BMI above the 97th percentile to a BMI on the 10th percentile relative to their age in the 3 months preceding hospitalization. The remaining five had had a BMI $<17.5$ in the previous 3 months but had been initially admitted to a medical ward. They had gained weight just before their transfer to a psychiatry unit and inclusion in the study; (b) 39 patients did not meet DSM-IV-TR Criterion B; (c) 16 patients did not meet DSM-IV-TR Criterion C; (d) 10 patients did not meet DSM-IV-TR Criterion D. We considered all the patients (AN full syndrome and subthreshold) in our analyses. The exclusion criteria for the present study were men $(n=10)$, age younger than 13 years ( $n=11$; age from which all patients had the same versions of the questionnaires of interest) and patients with negative values of FMI $(n=4)$. These values were observed in patients with very low-BMI values (10.34, $11.55,12.57$, and 13.34). They reflect the inadequacy of the bioelectrical impedance formula to calculate body fat in case of extreme emaciation associated with massive body water expansion. In addition, due to technical problems (inadequate electrodes), FFMI and FMI were not measured in 17 patients. Finally, 191 patients were included in the present study (Figure 1).

\section{3 | Exercise: Duration and intensity}

Participants were interviewed by trained evaluators, using a semistructured questionnaire (Rizk et al., 2015). This questionnaire was designed to determine at what

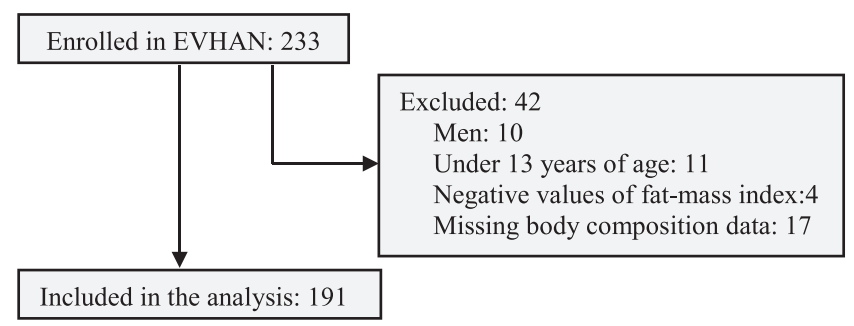

FIGURE 1 Flow diagram of number of patients included in the present analysis level patients were engaging in a given type of exercise in the month preceding hospitalization. It was intended to evaluate the type of exercise (walking, running, swimming, cycling, and household activities), frequency, and duration (in hours per week). At the end of the questionnaire, in an open question, patients were asked to specify any other activity they were practicing. Each exercise pattern was then matched with its intensity in metabolic equivalents (METs) using the compendium of physical activity proposed by Ainsworth et al. (2011). The MET value of each physical activity represents the ratio of the energy expended per kilogram of body weight per hour during the activity compared with the energy expended when sitting quietly. The number of hours spent per day on each activity was multiplied by its MET score. The daily amount of exercise was then obtained by summing the MET hours for all activities.

\section{4 | Nutritional status: BMI, FFMI, and FMI}

Three markers of the nutritional status were considered: BMI, FFMI, and FMI. Body weight was measured to the nearest $0.1 \mathrm{~kg}$ using standard beam balance scales (Omega-SECA, Germany). Height was measured to the nearest $0.1 \mathrm{~cm}$ using a stadiometer (wall-mounted model 222-SECA, Germany). BMI was derived from weight (kg) divided by the square of height (meters). FM and FFM were assessed in the first 2 weeks of admission to the inpatient unit. This allowed the stabilization of the patients' fluid and electrolytes status by sustaining from compensatory behaviors (purging, vomiting, or laxative/diuretic abuse; Piccoli, Codognotto, Di Pascoli, Boffo, \& Caregaro, 2005; Probst, Goris, Vandereycken, \& Van Coppenolle, 2001). FFM and FM were measured using the Bioelectrical Analyzer (FORANA, Helios, Frankfurt, Germany) with an alternating electric current at $50 \mathrm{kHz}$ and $800 \mathrm{mAmp}$, four skin electrodes (BIANOSTIC, DataInput, Darmstadt, Germany), and using the Deurenberg equation as previously described in the study of Mattar et al. (Mattar, Huas, Group, \& Godart, 2012). FMI and FFMI were calculated to evaluate fat mass and fat-free mass independently of height (Kyle, Schutz, Dupertuis, \& Pichard, 2003). FMI and FFMI are the equivalent of fat mass (in $\mathrm{kg}$ ) and fat-free mass $(\mathrm{kg}$ ) divided by squared height $(\mathrm{m})$, respectively. Given that our sample includes women aged between 13 and 52, normal FMI references ranged from $3.4 \mathrm{~kg} / \mathrm{m}^{2}$ (fifth percentile) to $9.9 \mathrm{~kg} / \mathrm{m}^{2}$ (95th percentile), and normal FFMI references ranged from $13.8 \mathrm{~kg} / \mathrm{m}^{2}$ (fifth percentile) to $18 \mathrm{~kg} / \mathrm{m}^{2}$ (95th percentile; Schutz, Kyle, \& Pichard, 2002). 


\section{WILEY}

\section{5 | Confounding factors}

The body composition of patients with AN is affected by factors that could either be specifically linked to their disorder (AN subtype (Probst et al., 1996), age at illness onset (Mattar, Huas, et al., 2012), illness duration (Mattar, Huas, et al., 2012), premenarchal AN (Demerath et al., 2004), and presence of amenorrhea (Pitts, Blood, Divasta, \& Gordon, 2014) or by factors also found in the general population (age (Zamboni et al., 1997) and birth weight (Mattar, Pichard, Godart, \& Melchior, 2012).

These elements were evaluated by the CIDI 3.0 (WHO, 1997) for AN characteristics and by the study questionnaire for other elements.

\section{6 | Statistics}

A statistical analysis was performed using SPSS software (SPSS Statistics, version 21.0; Chicago). First descriptive statistics were produced. Numerical variables were summarized as mean and standard deviation, whereas counts and frequencies were used for categorical variables. Associations between nutritional status markers (BMI, FFMI, and FMI), exercise duration and exercise intensity, and other confounding variables (age, age at AN onset, illness duration, birth weight, premenarchal AN status, and AN subtypes) were tested using the appropriate univariate analysis (the Chi-squared test and the Student $t$ test). If assumptions of parametric counterparts (normality and homoscedasticity) were not met and if two-group comparisons had highly imbalanced sample size, nonparametric tests were used (the Mann-Whitney U test). A fixed Type I error of 5\% was considered. Finally, linear multiple regression analyses were carried out using BMI, FFMI, and FMI as dependent variables and including systematically exercise duration, exercise intensity, and other confounding variables that were significantly associated with each dependent variable in univariate tests $(p<0.1$; see results of univariate analysis for details).

\section{3 | RESULTS}

\section{1 | Patients' characteristics}

Characteristics of patients at admission to inpatient treatment are presented in Table 1. Very emaciated patients are presented, with mean values of BMI, FFMI, FMI, and percentage of body fat far below the normal values for healthy adult women.

Ninety-seven participants (50.8\%) met criteria for AN restrictive type (AN-R), and 94 participants (49.2\%) met criteria for the binge-eating/purging type. At admission to the inpatient program, $95.8 \%$ (183/191) of participants had premenarchal $\mathrm{AN}$, and $12 \%$ (23/191) had amenorrhea.

\section{2 | Links between physical exercise, BMI, body composition, and variables of interest}

Results of univariate tests between BMI, FFMI, FMI, clinical characteristics (age, age at AN onset, illness duration, birth weight, AN subtypes, premenarchal AN status, and presence of amenorrhea), and exercise (duration and intensity) are presented in Table 2. Exercise intensity was positively correlated to BMI $(p<0.05)$ and FFMI $(p<0.001)$ but not to FMI. However, exercise duration was not significantly correlated to any of the three markers of the nutritional state. BMI was significantly

TABLE 1 Patients characteristics with acute anorexia nervosa $(n=191)$

\begin{tabular}{|c|c|c|c|c|}
\hline & Mean & SD & Minimum & Maximum \\
\hline Age at AN onset (years) & 16.4 & 4.2 & 6.0 & 33.0 \\
\hline Illness duration (years) & 4.4 & 4.4 & 0.2 & 24.2 \\
\hline Birth weight* (kg) & 3.2 & 0.4 & 1.3 & 4.6 \\
\hline Fat mass index & 2.0 & 1.1 & 0.1 & 5.1 \\
\hline Body fat (\%) & 13.4 & 6.3 & 0.94 & 28.0 \\
\hline Exercise duration (hr/week) & 9.0 & 10.2 & 0 & 60.0 \\
\hline
\end{tabular}

*Birth weight is obtained for 131 patients. 
TABLE 2 Results of univariate analyses between body mass index, fat-free mass index, fat-mass index and variables of interest

\begin{tabular}{|c|c|c|c|}
\hline & BMI & FFMI & FMI \\
\hline Age & $r=-0.00$ & $r=-0.26^{* * *}$ & $r=0.20^{* *}$ \\
\hline Age at AN onset & $r=0.08$ & $r=0.04$ & $r=0.08$ \\
\hline Illness duration & $r=-0.02$ & $r=-0.28^{* * *}$ & $r=0.20^{*}$ \\
\hline Birth weight & $r=0.13$ & $r=0.18^{*}$ & $r=0.03$ \\
\hline Exercise duration & $r=-0.01$ & $r=-0.01$ & $r=0.00$ \\
\hline Exercise intensity & $r=0.15^{*}$ & $r=0.25^{* * *}$ & $r=0.01$ \\
\hline \multicolumn{4}{|l|}{ AN subtype ${ }^{t}$} \\
\hline $\mathrm{AN}-\mathrm{R}^{\dagger}$ & $14.2 \pm 1.3^{* * *}$ & $12.4 \pm 0.86^{* *}$ & $1.8 \pm 1.06^{* *}$ \\
\hline $\mathrm{AN}-\mathrm{BP}^{\dagger}$ & $15.0 \pm 1.5$ & $12.7 \pm 1.0$ & $2.3 \pm 1.2$ \\
\hline \multicolumn{4}{|l|}{ Premenarchal $\mathrm{AN}^{\mathrm{t}}$} \\
\hline Yes $^{\dagger}$ & $14.1 \pm 1.0^{*}$ & $12.2 \pm 0.6^{*}$ & $1.9 \pm 0.8$ \\
\hline $\mathrm{No}^{\dagger}$ & $14.6 \pm 1.5$ & $12.6 \pm 0.8$ & $2.0 \pm 1.1$ \\
\hline \multicolumn{4}{|l|}{ Amenorrhea ${ }^{\S}$} \\
\hline Yes $^{\dagger}$ & $14.5 \pm 1.4^{*}$ & $12.5 \pm 0.8^{*}$ & $2.0 \pm 1.1$ \\
\hline $\mathrm{No}^{\dagger}$ & $16.3 \pm 2.1$ & $13.2 \pm 0.8$ & $3.1 \pm 1.6$ \\
\hline
\end{tabular}

$r$ : Pearson's correlation coefficients. ${ }^{\mathrm{t}}: t$ test for independent samples.

$\S$ : Mann-Whitney test for independent samples. ${ }^{\dagger}$ : Mean \pm SD.

${ }^{*} p \leq 0.05 .{ }^{* *} p \leq 0.01 .{ }^{* * *} p \leq 0.001$.

Note. AN: anorexia nervosa; AN-BP: anorexia nervosa binge-eating/purging type; AN-R: anorexia nervosa restrictive type; FFMI: fat-free mass index; FMI: fat mass index.

correlated to FFMI $(r=0.663, p<0.001)$ and FMI $(r=0.823, p<0.001)$. Age was negatively linked to FFMI and positively to FMI. Birth weight was only positively correlated to FFMI $(p<0.05)$. Both amenorrhea and premenarchal AN were linked to lower BMI and FFMI $(p<0.05)$. There was a tendency for a lower FMI in patients with amenorrhea $(p=0.054)$.

\section{3 | Impact of physical exercise on BMI, FFMI, or FMI as dependent variables}

The results of the multivariate regressions are presented in Table 3. These analyses were performed to explore the extent to which exercise (in terms of duration and intensity) and other variables of interest, significantly identified in univariate analysis (Table 2), predicted BMI, FFMI, and FMI. Current age was highly correlated to illness duration $(r=0.722, p<0.001)$ and age at AN onset ( $r=0.687, p<0.001)$. Premenarchal AN status was linked to age at AN onset $(p<0.001)$. Thus, only age and premenarchal AN status were included in our analyses.

A lower BMI was independently and significantly linked to a lower intensity of exercise, AN-R, and presence of amenorrhea (Table 3). The total variance accounted for by the model was $14.2 \%, F(5$, $185)=7.31, p<0.001$.

A lower FFMI was independently and significantly linked to lower intensity of exercise, an older age, AN$\mathrm{R}$, and premenarchal AN (Table 3). The total variance accounted for by the model was $19.2 \%, F(6$, $184)=8.53, p<0.001$.

These results were not modified when we added birth weight as a predictive variable (only available for 131 patients), and FFMI was also independently and significantly associated to higher birth weight; the total variance accounted for by this last model was $21.2 \%, F(7$, 123) $=5.99, p<0.001$ (Table 3 ).

A lower FMI was independently and significantly linked to AN-R, a younger age, and presence of amenorrhea (Table 3). The total variance accounted for by the model was $11.3 \%, F(5,185)=5.82, p<0.001$.

\section{4 | DISCUSSION}

To our knowledge, this is the first study to examine the links between the duration and intensity of physical exercise and nutritional status of patients with acute AN, while considering factors specific and nonspecific to AN.

Higher intensity of physical exercise was linked to higher BMI and FFMI. On one hand, it seems that patients with higher BMI had the strength and energy to exercise at higher intensities, which is in accordance with the results of Nagata et al. (2018), Falk, Halmi, and Tryon (1985) and Hechler et al. (2008). Because the most exhausted patients are generally the ones with the lowest BMI values, it was not surprising to find that these patients also had the lowest exercise intensity. This is most probably the consequence of their malnutrition and declining energy and physical capacities. On the other hand, it seems that exercise could keep a patient's BMI from further decreasing during the acute phase of the disorder. Individuals who exercise at high intensities could "allow" themselves to eat more and consequently, have a higher BMI. This is a topic of debate (Gümmer et al., 2015), but it was initially proposed by Garner and his colleagues in 1997. In fact, physical activity has been found to play an enhancing role in patients' weight recovery, especially in recovering body fat (Kostrzewa et al., 2013). This hypothesis is also in accordance with animal models. As mentioned in Section 1, Mequinion et al. (Méquinion et al., 2015) reported that in case of food restriction, the mice who exercised stabilized their weight faster in comparison with those who did not. Our finding suggests the need to reevaluate the general viewpoint that physical exercise only 
TABLE 3 Relationship among nutritional status markers and significant variables of interest

\begin{tabular}{|c|c|c|c|c|c|c|}
\hline \multirow[b]{2}{*}{ Outcome variable } & \multicolumn{2}{|c|}{ Model Summary } & \multicolumn{4}{|c|}{$\begin{array}{l}\text { Linear Regression } \\
\text { Regression Coefficients }\end{array}$} \\
\hline & Adjusted $\mathbf{R}^{2}$ & $p$ & & $\beta$ & $\mathbf{t}$ & $p$ \\
\hline \multirow[t]{3}{*}{ Body mass index } & \multirow[t]{3}{*}{0.142} & \multirow[t]{3}{*}{$<0.001$} & Exercise intensity & 0.151 & 2.139 & 0.034 \\
\hline & & & Exercise duration & -0.042 & -0.596 & 0.552 \\
\hline & & & Amenorrhea & -0.238 & -3.503 & 0.001 \\
\hline \multirow[t]{5}{*}{ Fat-free mass index* } & \multirow[t]{5}{*}{0.192} & \multirow[t]{5}{*}{$<0.001$} & Exercise intensity & 0.227 & 3.290 & 0.001 \\
\hline & & & Exercise duration & -0.008 & -0.110 & 0.913 \\
\hline & & & Age & -0.304 & -4.287 & $<0.001$ \\
\hline & & & Amenorrhea & -0.121 & -1.832 & 0.069 \\
\hline & & & AN subtype & -0.186 & -2.816 & 0.005 \\
\hline \multirow{5}{*}{ Fat-free mass index ${ }^{* *}$} & \multirow{5}{*}{0.212} & \multirow{5}{*}{$<0.001$} & Age & -0.272 & -3.191 & 0.002 \\
\hline & & & Amenorrhea & -0.101 & -1.255 & 0.212 \\
\hline & & & AN subtype & -0.170 & -2.147 & 0.034 \\
\hline & & & Premenarchal AN & -0.252 & -2.974 & 0.004 \\
\hline & & & Birth weight & 0.234 & 2.924 & 0.004 \\
\hline \multirow[t]{5}{*}{ Fat mass index } & \multirow[t]{5}{*}{0.113} & \multirow[t]{5}{*}{$<0.001$} & Exercise intensity & 0.026 & 0.357 & 0.722 \\
\hline & & & Exercise duration & -0.048 & -0.646 & 0.519 \\
\hline & & & Age & 0.212 & 2.989 & 0.003 \\
\hline & & & Amenorrhea & -0.218 & -3.173 & 0.002 \\
\hline & & & AN subtype & -0.226 & -3.284 & 0.001 \\
\hline
\end{tabular}

The use of bold emphasize in this table is to highlight significant results.

*Regression analysis excluding the predictor variable birth weight.

**Regression analysis including the predictor variable birth weight.

worsens clinical status in AN. Indeed, the positive association between exercising at high intensity and a better nutritional status (higher BMI and FFMI values) is in line with the idea of including adapted physical activity sessions in AN treatment (Ng et al., 2013). Moderated under the appropriate conditions (adapted to the food intake and energy expenditure of the patient and taking into account bone mineral density and cardiac function (American Psychiatric Association, 2006), supervised exercise interventions integrated in AN inpatient treatment appeared to be safe (Fernandez-del-Valle et al., 2014; Hausenblas et al., 2008; Ng et al., 2013; Vancampfort et al., 2014; Zunker et al., 2011), preserved bone mineral density (Achamrah et al., 2016), helped manage mood and anxiety (Achamrah et al., 2016), and were associated with a positive outcome and a significant decrease in patients' concerns about body weight and shape (Zunker et al., 2011). These interventions may also increase the compliance with outpatient treatment (Thien, Thomas, Markin, \& Birmingham, 2000). After summarizing the evidence of eight randomized controlled trials, Vancampfort et al. (2014) concluded that adapted exercise sessions significantly increased BMI, percentage of body fat, and muscular strength of patients with AN and that aerobic exercises, yoga, and massages significantly decreased eating disorder symptomatology and depressive symptoms in these patients.

Exercise duration (in terms of hours per week) was not linked to any of the three markers of nutritional status, which is in accordance with previous studies (Kostrzewa et al., 2013; Pirke, Trimborn, Platte, \& Fichter, 1991). However, some studies did find positive (Casper et al., 1991) or negative (Hechler et al., 2008) associations between BMI, percentage of body fat, and the level of daily physical activity in outpatients. These conflicting results could be explained by methodological discrepancies (small samples with 30 or less participants, nonvalidated method to measure body composition in $\mathrm{AN}$, and/or not considering confounding factors in multivariate analyses; Rizk et al., 2015).

The restrictive subtype of AN contributed to explain a worse nutritional state, which has been previously found in patients for BMI (Godart et al., 2006) and FMI (Probst et al., 1996). FFMI was positively linked to birth weight, 
which is in accordance with results from the general population (Singhal, Wells, Cole, Fewtrell, \& Lucas, 2003) and in AN.

The presence of amenorrhea was significantly linked to lower BMI and FMI. This is in accordance with previous studies in the general population and in AN (Abraham, Pettigrew, Boyd, \& Russell, 2006; Ahima, 2004). Pitts et al. (2014) found that patients who recovered their menses had significantly higher percentages of body fat than the ones who did not.

Finally, older age was associated with lower FFMI and higher FMI. To our knowledge, this has not been previously investigated in AN. However, these findings are in line with results from the general population; in healthy individuals, BMI and percentage of body fat increase significantly with age (up to middle age; Shimokata et al., 1991).

\section{5 | STRENGTH AND LIMITATIONS}

The main strengths of this study were (a) the use of a validated bioelectrical impedance analysis equation in AN (Mattar et al., 2011) to assess body composition in a very large sample of inpatients; (b) the focus on physical exercise and not on excessive exercise; and (c) simultaneous consideration of several factors associated with the nutritional status of patients. To our knowledge, this has not been done before.

The main limitation was the lack of information concerning the food intake and energy expenditure of patients. Both these factors have been reported to significantly predict the nutritional status of healthy individuals (Thibault, Genton, \& Pichard, 2012) and patients with AN (Mitchell \& Truswell, 1987). Considering energy intake and energy expenditure would have brought more insights to understanding our patients' nutritional statuses. Future research should investigate these parameters in addition to the factors investigated in this study. Another limitation was the use of a subjective method to assess the duration and intensity of exercise. Using an objective method, such as accelerometers, in our huge cohort would have been very difficult to implement and expensive. The use of a semistructured questionnaire seemed more appropriate (Davis, Kennedy, Ravelski, \& Dionne, 1994). Nevertheless, the use of the compendium of physical activity proposed by Ainsworth et al. (2011) is a validated measure of exercise intensity and energy expenditure (Strath et al., 2013). Future studies could benefit more from including an objective instrument in their protocols to assess both physical activity and energy expenditure. In addition, the BMI range of our sample was very broad (11.2-18.6). This could have influenced exercise intensity during the month before hospitalization. We did not evaluate weight variations 1 month prior to hospitalization, during which some patients might have lost weight, and others gained or stabilized. Future studies are needed to investigate this point. Finally, it is important to note that the cross-sectional design of our study investigates associations rather than causality.

\section{6 | CONCLUSION}

Exercising at higher intensity in acute AN is associated with a better nutritional status, thus, a better resistance to starvation, similarly to animal models. The impact of therapeutic physical activity sessions, adapted in terms of exercise intensity and a patient's clinical status, should be evaluated during the nutrition rehabilitation process. Over exercising in AN has also been strongly known to have a negative impact on clinical outcome; however, how much physical activity is too much physical activity is also an important question to raise. New research proposing a structured physical activity program in AN treatment and evaluating its effects in a large randomized control trial are needed.

\section{ACKNOWLEDGEMENTS}

We would like to acknowledge all the participants for their commitment to the study. EVHAN study was supported by grants from the French Ministry of Health (PHRCN 2007, 2011 AOM11197; ANR Jeune chercheur, Bourse de thèse Eiffel) and from CNAM-TS, Fondation de France, Fondation MGEN, EHESP, AP-HP, CIFRE, and Contrats d'interface INSERM.

Members of the EVHAN Group: Nathalie Godart; Sylvie Berthoz; Jeanne Duclos; Lama Mattar; Hélène Roux; Marie Raphaële Thiébaud; Christophe Lalanne; Sarah Vibert; Tamara Hubert; Annaig Courty; Damien Ringuenet; Jean-pierre Benoit; Corinne Blanchet; MarieRose Moro; Laura Bignami; Clémentine Nordon; Frédéric Rouillon; Solange Cook; Catherine Doyen; MarieChristine Mouren Siméoni; Priscille Gerardin; Sylvie Lebecq; Marc-Antoine Podlipski; Claire Gayet; Malaika Lasfar; Marc Delorme; Xavier Pommereau; Stéphanie Bioulac; Manuel Bouvard; Jennifer Carrere; Karine Doncieux; Sophie Faucher; Catherine Fayollet; Amélie Prexl; Stéphane Billard; François Lang; Virginie Mourier-Soleillant; Régine Greiner; Aurélia Gay; Guy Carrot; Sylvain Lambert; Morgane Rousselet; Ludovic Placé; Jean-luc Venisse; Marie Bronnec; Bruno Falissard; Christophe Genolini; Christine Hassler; Jean-Marc Tréluyer; Olivier Chacornac; Maryline Delattre; Nellie Moulopo; Christelle Turuban; Christelle Auger. 


\section{STATEMENT OF AUTHORSHIP}

M. R. and N. G. designed the study and drafted the manuscript. N. G. conceived the study. Members of EVHAN group participated in recruiting patients, collecting data, and obtaining funding. C. L. advised on the statistical analysis. L. K., M. H., L.M., J. C. M., S. B., and N. G. participated in the interpretation of the data and drafted the manuscript. C. P. actively corrected the draft of the manuscript. All authors claimed authorship and made substantial contributions to the conception, drafting, and final version of the manuscript. All authors have approved the final article, and none of them had a conflict of interest.

\section{ORCID}

\section{Melissa Rizk (D) https://orcid.org/0000-0002-8148-8401}

\section{REFERENCES}

Abraham, S. F., Pettigrew, B., Boyd, C., \& Russell, J. (2006). Predictors of functional and exercise amenorrhoea among eating and exercise disordered patients. Human Reproduction, 21(1), 257-261. https://doi.org/10.1093/humrep/dei294

Achamrah, N., Nobis, S., Breton, J., Jésus, P., Belmonte, L., Maurer, B., ... Coëffiera, M. (2016). Maintaining physical activity during refeeding improves body composition, intestinal hyperpermeability and behavior in anorectic mice. Scientific Reports, 6, 21887. https://doi.org/10.1038/srep21887

Adan, R. A., Hillebrand, J. J., Danner, U. N., Cardona Cano, S., Kas, M. J., \& Verhagen, L. A. (2011). Neurobiology driving hyperactivity in activity-based anorexia. Current Topics in Behavioral Neurosciences, 6, 229-250.

Ahima, R. S. (2004). Body fat, leptin, and hypothalamic amenorrhea. The New England Journal of Medicine, 351(10), 959-962. https://doi.org/10.1056/NEJMp048214

Ainsworth, B. E., Haskell, W. L., Herrmann, S. D., Meckes, N., Bassett, D. R. Jr., Tudor-Locke, C., ... Leon, A. S. (2011). 2011 Compendium of Physical Activities: A second update of codes and MET values. Medicine and Science in Sports and Exercise, 43(8), 1575-1581. https://doi.org/10.1249/ MSS.0b013e31821ece12

APA (2013). Diagnostic and statistical manual of mental disorders (Fifth ed.). Arlington, VA: American Psychiatric Publishing.

Association, A. P. (2006). Practice guideline for the treatment of patients with eating disorders. Third edition. Retrieved from http://psychiatryonline.org/pb/assets/raw/sitewide/practice_ guidelines/guidelines/eatingdisorders.pdf

Casper, R. C., Schoeller, D. A., Kushner, R., Hnilicka, J., \& Gold, S. T. (1991). Total daily energy expenditure and activity level in anorexia nervosa. The American Journal of Clinical Nutrition, 53(5), 1143-1150. https://doi.org/10.1093/ajen/53.5.1143

Caspersen, C. J., Powell, K. E., \& Christenson, G. M. (1985). Physical activity, exercise, and physical fitness: Definitions and distinctions for health-related research. Public Health Reports, 100(2), 126-131.

Cooper, Z., Cooper, P. J., \& Fairburn, C. G. (1989). The validity of the eating disorder examination and its subscales. The British Journal of Psychiatry, 154(6), 807-812. https://doi.org/10.1192/ bjp.154.6.807

Davis, C., Kennedy, S. H., Ravelski, E., \& Dionne, M. (1994). The role of physical activity in the development and maintenance of eating disorders. Psychological Medicine, 24(4), 957-967. https://doi.org/10.1017/S0033291700029044

Demerath, E. W., Li, J., Sun, S. S., Chumlea, W. C., Remsberg, K. E., Czerwinski, S. A., ... Siervogel, R. M. (2004). Fifty-year trends in serial body mass index during adolescence in girls: The Fels Longitudinal Study. The American Journal of Clinical Nutrition, 80(2), 441-446. https://doi.org/10.1093/ajcn/80.2.441

El Ghoch, M., Calugi, S., Pellegrini, M., Milanese, C., Busacchi, M., Battistini, N. C., ... Dalle Grave, R. (2013). Measured physical activity in anorexia nervosa: Features and treatment outcome. The International Journal of Eating Disorders, 46(7), 709-712. https://doi.org/10.1002/eat.22140

Falk, J. R., Halmi, K. A., \& Tryon, W. W. (1985). Activity measures in anorexia nervosa. Archives of General Psychiatry, 42(8), 811-814. https://doi.org/10.1001/archpsyc.1985.01790310073010

Fernandez-del-Valle, M., Larumbe-Zabala, E., VillaseñorMontarroso, A., Cardona Gonzalez, C., Diez-Vega, I., Lopez Mojares, L. M., \& Perez Ruiz, M. (2014). Resistance training enhances muscular performance in patients with anorexia nervosa: A randomized controlled trial. The International Journal of Eating Disorders, 47(6), 601-609. https://doi.org/10.1002/ eat.22251

Garner, D., \& Garfinkel, P. (1997). Handbook of treatment for eating disorders (2nd ed.). New York, NY: The Guilford Press.

Godart, N., Berthoz, S., Rein, Z., Perdereau, F., Lang, F., Venisse, J. L., ... Curt, F. (2006). Does the frequency of anxiety and depressive disorders differ between diagnostic subtypes of anorexia nervosa and bulimia? The International Journal of Eating Disorders, 39(8), 772-778. https://doi.org/10.1002/eat.20274

Gümmer, R., Giel, K., Schag, K., Resmark, G., Junne, F., Becker, S., ... Teufel, M. (2015). High levels of physical activity in anorexia nervosa: A systematic review. European Eating Disorders Review, 23, 333-344. https://doi.org/10.1002/erv.2377

Hausenblas, H. A., Cook, B. J., \& Chittester, N. I. (2008). Can exercise treat eating disorders? Exercise and Sport Sciences Reviews, 36(1), 43-47. https://doi.org/10.1097/jes.0b013e31815e4040

Hebebrand, J., Himmelmann, G. W., Herzog, W., HerpertzDahlmann, B. M., Steinhausen, H. C., Amstein, M., ... Schäfer, H. (1997). Prediction of low body weight at long-term followup in acute anorexia nervosa by low body weight at referral. The American Journal of Psychiatry, 154(4), 566-569. https:// doi.org/10.1176/ajp.154.4.566

Hechler, T., Rieger, E., Touyz, S., Beumont, P., Plasqui, G., \& Westerterp, K. (2008). Physical activity and body composition in outpatients recovering from anorexia nervosa and healthy controls. Adapted Physical Activity Quarterly, 25(2), 159-173. https://doi.org/10.1123/apaq.25.2.159 
Huas, C., Caille, A., Godart, N., Foulon, C., Pham-Scottez, A., Divac, S., ... Falissard, B. (2011). Factors predictive of ten-year mortality in severe anorexia nervosa patients. Acta Psychiatrica Scandinavica, 123(1), 62-70. https://doi.org/10.1111/j.16000447.2010.01627.x

Kostrzewa, E., van Elburg, A. A., Sanders, N., Sternheim, L., Adan, R. A., \& Kas, M. J. (2013). Longitudinal changes in the physical activity of adolescents with anorexia nervosa and their influence on body composition and leptin serum levels after recovery. PLoS One, 8(10), e78251. https://doi.org/10.1371/journal. pone.0078251

Kyle, U. G., Schutz, Y., Dupertuis, Y. M., \& Pichard, C. (2003). Body composition interpretation. Contributions of the fat-free mass index and the body fat mass index. Nutrition, 19(7-8), 597-604. https://doi.org/10.1016/S0899-9007(03)00061-3

Mattar, L., Godart, N., Melchior, J. C., Falissard, B., Kolta, S., Ringuenet, D., ... Pichard, C. (2011). Underweight patients with anorexia nervosa: comparison of bioelectrical impedance analysis using five equations to dual X-ray absorptiometry. Clinical Nutrition, 30(6), 746-752. https://doi.org/10.1016/j. clnu.2011.05.012

Mattar, L., Huas, C., Group, E., \& Godart, N. (2012). Relationship between affective symptoms and malnutrition severity in severe anorexia nervosa. PLoS One, 7(11), e49380. https://doi.org/ 10.1371/journal.pone.0049380

Mattar, L., Pichard, C., Godart, N., \& Melchior, J. C. (2012). Can birth weight predict later body composition in anorexia nervosa? European Journal of Clinical Nutrition, 66(8), 964-967. https:// doi.org/10.1038/ejcn.2012.21

Méquinion, M., Caron, E., Zgheib, S., Stievenard, A., Zizzari, P., Tolle, V., ... Viltart, O. (2015). Physical activity: benefit or weakness in metabolic adaptations in a mouse model of chronic food restriction? American Journal of Physiology. Endocrinology and Metabolism, 308(3), E241-E255. https://doi.org/10.1152/ ajpendo.00340.2014

Miller, K. K., Grinspoon, S. K., Ciampa, J., Hier, J., Herzog, D., \& Klibanski, A. (2005). Medical findings in outpatients with anorexia nervosa. Archives of Internal Medicine, 165(5), 561-566. https://doi.org/10.1001/archinte.165.5.561

Mitchell, P., \& Truswell, A. (1987). Body composition in anorexia nervosa and starvation. In J. Beumont, G. Burrows, \& R. Casper (Eds.), Handbook of eating disorders. Part I. anorexia and bulimia nervosa (pp. 45-77). Amsterdam: Elsevier.

Nagata, J., Carlson, J., Golden, N., Murray, S., Long, J., Leonard, M., \& Peebles, R. (2018). Associations between exercise, bone mineral density, and body composition in adolescents with anorexia nervosa. Eating and Weight Disorders - Studies on Anorexia, Bulimia and Obesity, 1-7. https://doi.org/10.1007/ s40519-018-0521-2

Ng, L. W., Ng, D. P., \& Wong, W. P. (2013). Is supervised exercise training safe in patients with anorexia nervosa? A metaanalysis. Physiotherapy, 99(1), 1-11. https://doi.org/10.1016/j. physio.2012.05.006

Piccoli, A., Codognotto, M., Di Pascoli, L., Boffo, G., \& Caregaro, L. (2005). Body mass index and agreement between bioimpedance and anthropometry estimates of body compartments in anorexia nervosa. JPEN Journal of Parenteral and Enteral Nutrition, 29(3), 148-156. https://doi.org/10.1177/0148607105029003148

Pirke, K. M., Trimborn, P., Platte, P., \& Fichter, M. (1991). Average total energy expenditure in anorexia nervosa, bulimia nervosa, and healthy young women. Biological Psychiatry, 30(7), 711-718. https://doi.org/10.1016/0006-3223(91)90016-F

Pitts, S., Blood, E., Divasta, A., \& Gordon, C. M. (2014). Percentage body fat by dual-energy X-ray absorptiometry is associated with menstrual recovery in adolescents with anorexia nervosa. The Journal of Adolescent Health, 54(6), 739-741. https://doi.org/ 10.1016/j.jadohealth.2013.12.033

Probst, M., Goris, M., Vandereycken, W., \& Van Coppenolle, H. (1996). Body composition in female anorexia nervosa patients. The British Journal of Nutrition, 76(5), 639-647. https://doi.org/ 10.1079/BJN19960072

Probst, M., Goris, M., Vandereycken, W., \& Van Coppenolle, H. (2001). Body composition of anorexia nervosa patients assessed by underwater weighing and skinfold-thickness measurements before and after weight gain. The American Journal of Clinical Nutrition, 73(2), 190-197. https://doi.org/10.1093/ajcn/73.2.190

Rizk, M. (2015). Implications of hyperactivity in anorexia nervosa: From redefinition to clinical research. (PhD), Sorbonne Paris Cité.

Rizk, M., Kern, L., Godart, N., \& Melchior, J.-C. (2014). Anorexie Mentale, activité physique et nutrition: quelles potentialisations ? Nutrition Clinique et Métabolisme, 28(4), 7.

Rizk, M., Lalanne, C., Berthoz, S., Kern, L., Godart, N., \& Group, E. (2015). Problematic exercise in anorexia nervosa: Testing potential risk factors against different definitions. PLoS One, 10(11), e0143352. https://doi.org/10.1371/journal.pone.0143352

Roux, H., Chapelon, E., \& Godart, N. (2013). Epidemiology of anorexia nervosa: A review. Encephale, 39(2), 85-93. https:// doi.org/10.1016/j.encep.2012.06.001

Schutz, Y., Kyle, U., \& Pichard, C. (2002). Fat-free mass index and fat mass index percentiles in Caucasians aged 18-98 y. International Journal of Obesity and Related Metabolic Disorders, 26(7), 953-960. https://doi.org/10.1038/sj.ijo.0802037

Shimokata, H., Andres, R., Coon, P., Elahi, D., Muller, D., Tobin, J., ... Seidell, J. (1991). Sex and age specific prediction formulas for estimating body composition from bioelectrical impedance: a cross-validation study. International Journal of Obesity, 15(1).

Singhal, A., Wells, J., Cole, T. J., Fewtrell, M., \& Lucas, A. (2003). Programming of lean body mass: A link between birth weight, obesity, and cardiovascular disease? The American Journal of Clinical Nutrition, 77(3), 726-730. https://doi.org/10.1093/ajcn/ 77.3.726

Solenberger, S. E. (2001). Exercise and eating disorders: A 3-year inpatient hospital record analysis. Eating Behaviors, 2(2), 151-168. https://doi.org/10.1016/S1471-0153(01)00026-5

Strath, S. J., Kaminsky, L. A., Ainsworth, B. E., Ekelund, U., Freedson, P. S., Gary, R. A., ... American Heart Association Physical Activity Committee of the Council on Lifestyle and Cardiometabolic Health and Cardiovascular, E., C.rdiac Rehabilitation and Prevention Committee of the Council on Clinical Cardiology, and Council (2013). Guide to the assessment of physical activity: Clinical and research applications: A scientific statement from the American Heart Association. 
Circulation, 128(20), 2259-2279. https://doi.org/10.1161/01 cir.0000435708.67487.da

Thibault, R., Genton, L., \& Pichard, C. (2012). Body composition: Why, when and for who? Clinical Nutrition, 31(4), 435-447. https://doi.org/10.1016/j.clnu.2011.12.011

Thien, V., Thomas, A., Markin, D., \& Birmingham, C. L. (2000). Pilot study of a graded exercise program for the treatment of anorexia nervosa. The International Journal of Eating Disorders, 28(1), 101-106. https://doi.org/10.1002/(SICI)1098-108X(200 007)28:1<101::AID-EAT12>3.0.CO;2-V

Vancampfort, D., Vanderlinden, J., De Hert, M., Soundy, A., Adamkova, M., Skjaerven, L. H., ... Probst, M. (2014). A systematic review of physical therapy interventions for patients with anorexia and bulemia nervosa. Disability and Rehabilitation, 36(8), 628-634. https://doi.org/10.3109/09638288.2013.808271

WHO. (1997). Composite International diagnostic interview (CIDI).

WHO. (2010). Recommandations mondiales sur l'activité physique pour la santé.

Woodside, B. D., \& Staab, R. (2006). Management of psychiatric comorbidity in anorexia nervosa and bulimia nervosa. CNS Drugs, 20(8), 655-663. https://doi.org/10.2165/00023210200620080-00004
Zamboni, M., Armellini, F., Harris, T., Turcato, E., Micciolo, R., Bergamo-Andreis, I. A., \& Bosello, O. (1997). Effects of age on body fat distribution and cardiovascular risk factors in women. The American Journal of Clinical Nutrition, 66(1), 111-115. https://doi.org/10.1093/ajcn/66.1.111

Zschucke, E., Gaudlitz, K., \& Strohle, A. (2013). Exercise and physical activity in mental disorders: clinical and experimental evidence. Journal of Preventive Medicine and Public Health, 46(Suppl 1), S12-S21. https://doi.org/10.3961/ jpmph.2013.46.S.S12

Zunker, C., Mitchell, J. E., \& Wonderlich, S. A. (2011). Exercise interventions for women with anorexia nervosa: a review of the literature. The International Journal of Eating Disorders, 44(7), 579-584. https://doi.org/10.1002/eat.20862 